\title{
Australian perspective regarding recommendations for physical activity and exercise rehabilitation in pulmonary arterial hypertension
}

\author{
This article was published in the following Dove Press journal: \\ Journal of Multidisciplinary Healthcare \\ 19 December 2011 \\ Number of times this article has been viewed
}

\author{
Robin Fowler ${ }^{1-3}$ \\ Sue Jenkins ${ }^{2,3,5}$ \\ Andrew Maiorana ${ }^{2,4}$ \\ Kevin Gain 2,3,6,7 \\ Gerry O'Driscoll ${ }^{7-9}$ \\ Eli Gabbay ${ }^{1-3,7-9}$
}

\begin{abstract}
'Advanced Lung Disease Program, Royal Perth Hospital, ${ }^{2}$ School of Physiotherapy and Curtin Health Innovation Research Institute, Curtin University, ${ }^{3}$ Lung Institute of Western Australia (LIWA), Centre for Asthma, Allergy and Respiratory Research, University of Western Australia, ${ }^{4}$ Advanced Heart Failure and Cardiac Transplant Service, Royal Perth Hospital, ${ }^{5}$ Physiotherapy Department, Sir Charles Gairdner Hospital, ${ }^{6}$ Respiratory Medicine Department, Royal Perth Hospital, ${ }^{7}$ School of Medicine, University of Western Australia, ${ }^{8} \mathrm{School}$ of Medicine, University of Notre Dame, ${ }^{9}$ Heart and Lung Transplant Foundation of Western Australia, Perth, Western Australia, Australia
\end{abstract}

Aim: To determine the opinion of health care professionals within Australia, regarding acceptable levels of exertion and symptoms, and referral for exercise rehabilitation in patients with pulmonary arterial hypertension $(\mathrm{PAH})$.

Method: In 2010, 76 health care professionals at a specialist pulmonary hypertension meeting in Australia were surveyed using a self-administered questionnaire. The questionnaire included case studies of patients with PAH in World Health Organization (WHO) functional classes II-IV. For each case study, respondents were asked to report their opinion regarding the acceptable level of exertion and symptoms during daily activities, and whether they would refer the patient for exercise rehabilitation. Three additional questions asked about advice in relation to four specific physical activities.

Results: The response rate was 70\% $(\mathrm{n}=53)$. Overall, $58 \%$ of respondents recommended patients undertake daily activities 'as tolerated'. There was no consensus regarding acceptable levels of breathlessness or fatigue, but the majority of respondents considered patients should have no chest pain (73\%) and no more than mild light-headedness (92\%) during daily activities. Overall, $63 \%$ of respondents would have referred patients for exercise rehabilitation. There was little difference in opinion regarding the acceptable level of exertion or symptoms, or referral for exercise rehabilitation, according to functional class. However, the patients' functional class did influence the advice given regarding the specific physical activities.

Conclusion: In 2010, there were inconsistencies between individual health care professionals within Australia regarding appropriate levels of physical exertion and acceptable symptoms during daily activities. Almost two-thirds of the respondents reported they would refer patients for exercise rehabilitation.

Keywords: exercise rehabilitation, physical activity, pulmonary arterial hypertension

\section{Introduction}

Pulmonary arterial hypertension (PAH) is characterized by poor exercise tolerance and impaired functional capacity. In patients with left heart failure (LHF) and chronic obstructive pulmonary disease, similar impairments respond well to exercise rehabilitation. ${ }^{1-3}$ Until recently, however, exercise rehabilitation was discouraged for patients with PAH due to a perceived high risk of adverse outcomes associated with physical exertion. ${ }^{4}$ Historically, symptoms were used to guide physical activity and patients were advised to avoid exertion associated with lightheadedness, chest pain, or severe dyspnea. ${ }^{5}$ Otherwise, little consideration was given
Correspondence: Robin Fowler Box 2213 GPO, Perth,

Western Australia 6847

Tel +6I892248793

$\mathrm{Fax}+61892243866$

Email r.fowler@ecu.edu.au 
regarding recommendations for physical activity or exercise rehabilitation for individuals with $\mathrm{PAH}$.

The recent introduction of PAH specific therapy has led to improved central hemodynamics and prognosis for patients with $\mathrm{PAH} .{ }^{6}$ Despite therapy, however, many patients with PAH continue to experience significant impairment in physical function and quality of life. ${ }^{7}$ The benefits seen following exercise rehabilitation in patients with LHF and chronic obstructive pulmonary disease have been achieved in the absence of adverse events or clinical deterioration and exercise rehabilitation now constitutes an important adjunct to medical therapy in these populations. ${ }^{8,9}$ These findings have stimulated an interest in the effects of exercise rehabilitation in patients with $\mathrm{PAH}$, but, prior to a feasibility study published in Japanese in $2005,{ }^{10}$ there were no reports of exercise rehabilitation in this population. Between 2006 and June 2010, a further three studies, with a total of 51 subjects with PAH who had undergone rehabilitation, were published. ${ }^{11-13}$ Improvements in exercise capacity and quality of life were observed following rehabilitation, without any adverse events or clinical deterioration. ${ }^{10-13}$ Since June 2010, two further studies of exercise rehabilitation in subjects with PAH (with a total of 27 subjects) have been published. ${ }^{14,15}$

It is possible the paucity of data regarding the impact of physical activity and exercise on outcomes in PAH has made it difficult for clinicians to provide consistent advice regarding physical activity and to identify which patients are suitable for exercise rehabilitation. The aim of this study was to determine the consistency of approach by health care professionals who manage patients with PAH within Australia, regarding appropriate levels of exertion and acceptable symptoms during physical activity, and referral for exercise rehabilitation.

\section{Methods}

The study used a cross sectional design with data collected via a self-administered questionnaire. The questionnaire was developed by the investigators specifically for this study (see Appendix 1). Although responses were anonymous, respondents were asked to indicate the type of institution that they worked in, their professional position, and the number of new PAH cases seen each year.

Three scenarios reflective of clinical practice were presented as case studies. These case studies described adults with PAH, one in each of the WHO functional classes II, III and IV. The data presented for each case study included the hemodynamic status (ie, pulmonary artery pressure and pulmonary vascular resistance index) obtained from right heart catheter assessment, right ventricular function measured at rest on an echocardiogram, 6-minute walk distance, and arterial blood gas data. For each case scenario, participants were instructed to respond to the same seven questions in accordance with their usual clinical management. The first question asked if they would perform any additional investigations. The remaining questions were designed to obtain data pertaining to the recommendations the respondent would provide regarding daily activity, acceptable symptoms on exertion, and whether they would refer the patient described in the case study for exercise rehabilitation.

Three additional questions, regarding four specific physical activities, were asked to determine the advice the respondents would give to patients with $\mathrm{PAH}$, in each of the functional classes II-IV. These questions asked whether patients with PAH would be advised for or against lifting a $20 \mathrm{~kg}$ weight, exercising in a non-hospital gym, regularly using stairs and slopes, or adopting a sedentary lifestyle.

Piloting of the questionnaire was performed in a sample of seven health care professionals (medical practitioners, $\mathrm{n}=3$; nurses, $\mathrm{n}=2$; physiotherapists, $\mathrm{n}=2$ ) from the pulmonary hypertension clinic at a tertiary hospital (Royal Perth Hospital, Perth, Western Australia). These individuals were instructed to complete the questionnaire, and provide feedback about its ease of use, applicability, and length. No recommendations for change arose from this pilot study.

\section{Participants}

The survey was conducted at the Pulmonary Hypertension Perspectives Meeting (Sydney, Australia; Pfizer Pharmaceuticals Australia) in June 2010. Eighty-nine health care professionals who worked in pulmonary hypertension clinics within Australia attended the meeting. Seventy-six of these participants had a role in advising patients with $\mathrm{PAH}$ regarding physical activity and exercise. The remaining participants were pharmacists $(n=12)$ and a medical student $(n=1)$. Attendance was by invitation and the purpose of the meeting was to provide a forum for experts within the field of pulmonary hypertension to discuss best practice and future directions in the diagnosis and management of PAH.

This study was approved by the Human Research Ethics Committee of Curtin University. Participant consent was implied by return of the questionnaires.

\section{Data analysis}

Data analysis comprised descriptive statistics. Analysis was performed using SPSS software (v 18; SPSS Inc, Chicago, IL). 


\section{Results}

Fifty-three completed questionnaires were returned from participants who have a role providing advice to patients regarding daily activities, or in referring patients for exercise rehabilitation. This represents a response rate of $70 \%$. Some respondents did not answer all questions and therefore not all percentages presented in the results add to 100 .

\section{Demographics}

Demographic data of the 53 respondents who completed the questionnaire are presented in Table 1.

Responses to the questions reflecting usual clinical practice, in relation to the case studies and four specific physical activities, are summarized in Table 2. Data pertaining to the responses to all of the questions are presented in Appendix 1.

\section{Responses to questions relating to the case studies}

\section{Instructions for daily activity}

The majority of respondents (67\%) stated that they would have given the patients verbal advice and $33 \%$ would have given written advice.

Overall, $58 \%$ of respondents stated that they would advise the patients to undertake daily activities 'as tolerated', regardless of functional class (Table 2). The balance of respondents moderated their instructions according to functional class. For example, $25 \%$ advised moderate activity for patients in functional class II, $9 \%$ advised moderate activity for patients in functional class III, and only $4 \%$ advised moderate activity for patients in functional class IV (Table 2). Some respondents provided details on how their patients would have been guided regarding daily activities. These respondents reported that they would have: assessed the patient's exercise capacity, referred the patient for physiotherapy and/or pulmonary or cardiac rehabilitation, advised the patient to use oxygen therapy during activity, or

Table I Demographics of the 53 respondents

\begin{tabular}{lll}
\hline Type of institution & Tertiary & $4 \mathrm{I}(77)$ \\
& Secondary & $8(15)$ \\
& Private and public & $3(6)$ \\
& Other & $1(2)$ \\
Profession & Respiratory physician & $19(36)$ \\
& Cardiologist & $8(15)$ \\
& Rheumatologist & $6(11)$ \\
& Nurse & $19(36)$ \\
& Exercise physiologist & $1(2)$ \\
\hline
\end{tabular}

Note: Data are number of responses with percentages given in parentheses. advised the patient to undertake symptom-limited exertion (Appendix 1).

\section{Acceptable symptoms during daily activities}

Overall, the majority (92\%) of respondents considered that either no light-headedness (53\%) or mild light-headedness (39\%) was acceptable during daily activities. A minority $(7 \%)$ considered that moderate light-headedness was acceptable. With regard to chest pain, $73 \%$ of respondents considered that no chest pain was acceptable. A further $20 \%$ advised that mild chest pain was acceptable. For both lightheadedness and chest pain there was little variation according to functional class (Table 2).

In terms of the breathlessness experienced during physical activities, overall $20 \%$ of respondents considered minimal, $44 \%$ considered moderate and $31 \%$ considered breathlessness 'as tolerated' was acceptable during daily activities. However, more respondents considered moderate rather than minimal breathlessness (51\% vs $11 \%$, respectively) was acceptable for the patient in functional class IV. When considering fatigue levels during daily activities, overall $5 \%$ of respondents considered that no fatigue was acceptable. A further $27 \%$ considered minimal fatigue, $40 \%$ considered moderate fatigue, and $21 \%$ considered that fatigue 'as tolerated' was acceptable. With the exception of the different opinion pertaining to acceptable levels of breathlessness for patients in functional class IV compared to patients in classes II and III, there was little difference in the level of symptoms that was considered acceptable across the functional classes (Table 2).

\section{Referral for exercise rehabilitation}

Overall, $63 \%$ of respondents stated they would have referred patients for exercise rehabilitation and this did not vary depending on the patients' functional class (Table 2).

\section{Responses to questions regarding specific physical activities}

Respondents' advice regarding the recommendations for the four specific physical activities varied according to functional class. Fifty-seven percent of respondents would have advised for, and 36\% against, patients in functional class II lifting a $20 \mathrm{~kg}$ weight. The majority of respondents would have advised patients in functional class II to use a non-hospital gym $(70 \%)$ and to regularly use stairs and slopes (79\%). The majority of respondents would also have advised patients in functional class II against adopting a sedentary lifestyle (91\%). 
Table 2 Questionnaire responses from the 53 participants

\begin{tabular}{|c|c|c|c|c|}
\hline & & Class II & Class III & Class IV \\
\hline \multirow[t]{3}{*}{ Method to guide daily activity } & Verbal & 72 & 62 & 68 \\
\hline & Written & 38 & 25 & 36 \\
\hline & Refer on for instruction & 17 & 26 & 23 \\
\hline \multirow[t]{2}{*}{ Refer for exercise rehabilitation } & Yes & 62 & 60 & 66 \\
\hline & No & 38 & 32 & 34 \\
\hline \multirow[t]{3}{*}{ Recommended level of exertion during daily activities } & Mild & 6 & 13 & 23 \\
\hline & Moderate & 25 & 9 & 4 \\
\hline & As tolerated & 57 & 57 & 60 \\
\hline \multirow[t]{3}{*}{ Acceptable breathlessness during daily activities } & Minimal & 23 & 26 & 11 \\
\hline & Moderate & 44 & 38 & 51 \\
\hline & As tolerated & 30 & 28 & 34 \\
\hline \multirow[t]{4}{*}{ Acceptable fatigue during daily activities } & None & 6 & 8 & 2 \\
\hline & Minimal & 33 & 25 & 28 \\
\hline & Moderate & 37 & 34 & 50 \\
\hline & As tolerated & 22 & 25 & 17 \\
\hline \multirow[t]{4}{*}{ Acceptable light-headedness during daily activities } & None & 57 & 51 & 51 \\
\hline & Mild & 37 & 38 & 41 \\
\hline & Moderate & 4 & 4 & 6 \\
\hline & To syncope & 0 & 0 & 0 \\
\hline \multirow[t]{4}{*}{ Acceptable chest pain during daily activities } & None & 78 & 74 & 68 \\
\hline & Mild & 16 & 13 & 30 \\
\hline & Moderate & 2 & 4 & 0 \\
\hline & As tolerated & 4 & 2 & 2 \\
\hline \multirow[t]{2}{*}{ Would you advise a patient to lift a $20 \mathrm{~kg}$ weight } & Yes & 36 & 9 & 0 \\
\hline & No & 57 & 83 & 92 \\
\hline \multirow[t]{2}{*}{ Would you advise exercise in a non-hospital gym } & Yes & 70 & 21 & 6 \\
\hline & No & 23 & 72 & 87 \\
\hline \multirow[t]{2}{*}{ Would you advise regularly using stairs and slopes } & Yes & 79 & 51 & 11 \\
\hline & No & 13 & 42 & 81 \\
\hline \multirow[t]{2}{*}{ Would you advise a sedentary lifestyle } & Yes & 2 & 8 & 17 \\
\hline & No & 91 & 85 & 75 \\
\hline
\end{tabular}

Notes: Data are percentage of responses. Some respondents did not answer all questions and therefore not all percentages add to I00. Raw data for the responses to all questions are given in Appendix I.

For patients in functional class III, $83 \%$ of respondents would have advised against lifting a $20 \mathrm{~kg}$ weight and against exercise in a non-hospital gym (72\%). A similar number of respondents recommended that patients in functional class III did and did not regularly use stairs and slopes (51\% and $42 \%$, respectively). Eighty-five percent would have advised patients in functional class III against a sedentary lifestyle. The majority of respondents stated that they would have advised patients in functional class IV not to lift a $20 \mathrm{~kg}$ weight (92\%), not to use a non-hospital gym (87\%) and not to regularly use stairs or slopes $(81 \%)$. The majority of respondents would have advised patients in functional class IV to adopt a sedentary lifestyle (75\%).

\section{Discussion}

The main findings of this survey of health care professionals attending a pulmonary hypertension specific meeting in 2010 were: (1) there was inconsistency between individuals regarding the acceptable level of exertion, breathlessness and fatigue during daily activities for patients with $\mathrm{PAH}$; (2) there was a consensus that, for these patients, chest pain and anything more than mild light-headedness was not acceptable during daily activities; (3) approximately twothirds of respondents stated they would refer patients for exercise rehabilitation; (4) the level of acceptable symptoms during daily activities and patterns of referral for exercise rehabilitation did not vary greatly according to the patients' functional class, but, (5) advice regarding specific physical activities varied according to functional class.

The lack of evidence regarding the safety and impact of physical exertion on hemodynamics in patients with PAH has made it difficult for clinicians to provide recommendations regarding physical activity. Until recently, physical activity guidelines for patients with PAH were only available from sources such as the Pulmonary Hypertension Association ${ }^{5}$ and were based upon studies in subjects with LHF. Patients 
with PAH were advised to undertake light to moderate aerobic exercise and to avoid exercise to the point of lightheadedness, chest pain, or severe dyspnea. Patients with severe functional limitation, and those with a history of dizziness and/or fainting, were advised against undertaking an exercise program. ${ }^{5}$

The inconsistency in response in our study, regarding acceptable symptoms of breathlessness and fatigue during physical activity, is likely to reflect uncertainty about the significance of these symptoms. In contrast, the consensus regarding the avoidance of light-headedness, a symptom suggestive of impaired cardiac output, ${ }^{16}$ and the majority view recommending avoidance of chest pain, a symptom suggestive of myocardial ischemia, ${ }^{17}$ is likely to reflect the understanding that these symptoms can represent life threatening events. The inconsistencies in opinion regarding the appropriate level of exertion and advice for common daily activities, such as lifting a $20 \mathrm{~kg}$ weight and the regular use of stairs and slopes, suggests uncertainty about the impact of general physical activity on patient outcome.

Recently, one randomized controlled trial, ${ }^{11}$ one nonrandomized controlled trial, ${ }^{15}$ three intervention trials ${ }^{10,12,14}$ and one case report on exercise rehabilitation ${ }^{13}$ have been published. The subjects in these studies had idiopathic PAH ( $\mathrm{n}=83$ ), chronic thrombo-embolic pulmonary hypertension $(\mathrm{n}=8)$, or PAH associated with connective tissue disease $(n=10)$, or congenital heart disease $(n=1)$. These publications reported positive outcomes associated with exercise rehabilitation, achieved in the absence of adverse events. To the authors' knowledge, only one published position statement on pulmonary rehabilitation ${ }^{9}$ and no position statements or guidelines on cardiac rehabilitation include specific guidelines for exercise rehabilitation in PAH. In 2008, one publication reviewed exercise responses in PAH and discussed exercise prescription for this population. ${ }^{4}$

In the current study, the finding that only two-thirds of respondents recommended exercise rehabilitation for patients in functional classes II and III suggests that, in 2010, there was uncertainty regarding this intervention, despite publications describing benefits of exercise training for this population. ${ }^{10-13}$ This uncertainty may be related to the low number of subjects in the published reports and the publication of only one randomized controlled trial of exercise rehabilitation.

The only reported study of exercise rehabilitation that included a substantial number of patients in functional class IV was published in Japanese. ${ }^{10}$ However, in our study it was notable that the majority of respondents stated that they would refer patients in functional class IV for exercise rehabilitation, despite the very limited evidence for exercise rehabilitation in this subgroup. It is possible this finding relates to a perception that exercise rehabilitation for patients in functional class IV will improve functional capacity and minimize symptoms during activities of daily living. It may also relate to the perceived need for patients with severe disease to be educated about the risks of overexertion and to be supervised during exercise. The advice for patients in functional class IV, regarding the specific physical activities presented in this study, demonstrated a conservative approach towards physical activity that was not supervised by a health care professional.

The point prevalence of idiopathic PAH in Australia is estimated at 40 per million ${ }^{18}$ and therefore, based upon Australian population statistics, ${ }^{19}$ the estimated number of patients with idiopathic PAH in Australia is approximately 900. In 2010, medical practitioners in 47 pulmonary hypertension clinics were licensed to prescribe PAH specific pharmaceutical therapies. ${ }^{20}$ The rarity and complex nature of PAH, and strict licensing conditions associated with the prescription of PAH medications, means a limited number of health care professionals are involved in the management of patients with PAH. The relatively small number of participants in this study reflects the limited number of health care professionals, within Australia, who work with patients who have PAH.

\section{Limitations}

Attendance at the meeting at which the survey was performed was by invitation, resulting in likely selection bias. However, it also ensured the respondents were directly involved in the management of patients with PAH.

It was not possible to identify any overlap between respondents, in terms of the institutions that were represented, due to a deliberate decision to maintain the respondents' anonymity. However, the preservation of anonymity is likely to have had a positive influence over the response rate and encouraged open responses.

\section{Conclusion}

In 2010, health care professionals within Australia were inconsistent in opinion regarding appropriate levels of exertion and acceptable symptoms during daily activities. There appeared to be some uncertainty regarding the role of exercise rehabilitation in PAH. The findings of this study identify a need for further research to support the development of guidelines on physical activity and exercise rehabilitation for the PAH population in Australia. 


\section{Acknowledgments}

The authors would like to acknowledge Peter McKinnon, Curtin University, for assistance with the statistical analyses; and the staff of Pfizer Pharmaceuticals Australia, for assistance with photocopying, distribution, and collection of the surveys.

\section{Author contributions}

Robin Fowler was responsible for the design of this study, collection of the data, analysis and interpretation of the data and preparation of the manuscript. Sue Jenkins was responsible for the design of this study, interpretation of the data and preparation of the manuscript. Andrew Maiorana was responsible for the design of this study and preparation of the manuscript. Kevin Gain was responsible for analysis and interpretation of the data and preparation of the manuscript. Gerry O'Driscoll was responsible for the design of this study and preparation of the manuscript. Eli Gabbay was responsible for the design of this study, interpretation of the data and preparation of the manuscript.

\section{Disclosures}

This research was supported by Bayer Schering Pharmaceuticals and Actelion Pharmaceuticals Australia. Robin Fowler has received travel support from Bayer Schering, Actelion, and CSL and an Honorarium from Pfizer Australia. Andrew Maiorana has received travel support from Actelion. Eli Gabbay has received travel support, is on the Advisory Board and has received honoraria and research funding from Actelion and Pfizer. These funding bodies had no influence on the planning of this study, data collection, analysis or interpretation. Sue Jenkins, Kevin Gain, and Gerry O'Driscoll have no financial relationships with a commercial entity that has a commercial interest in the subject of the presented manuscript or other conflicts of interest to disclose.

The meeting organisers had no input or influence over the content of the questionnaire, the data analysis or this manuscript. They supported the project by photocopying, distributing, and collecting the questionnaires.

\section{References}

1. Belardinelli R, Georgiou D, Cianci G, Purcaro A. Randomised controlled trial of long-term moderate exercise training in chronic heart failure: effects on functional capacity, quality of life, and clinical outcome. Circulation. 1999;99(9):1173-1182.
2. Maiorana A, O’Driscoll G, Cheetham C, et al. Combined aerobic and resistance exercise training improves functional capacity and strength in CHF. J Appl Physiol. 2000;88(5):1565-1570.

3. Ries AL, Bauldoff GS, Carlin BW, et al. Pulmonary rehabilitation: joint ACCP/AACVPR evidence-based clinical practice guidelines. Chest. 2007;131(5 Suppl):4S-42S.

4. Desai SA, Channick RN. Exercise in patients with pulmonary arterial hypertension. J Cardiopulm Rehab Prev. 2008;28(1):12-16.

5. Pulmonary Hypertension Association. Consensus statements. Recommendations for exercise in patients with PAH. Available at: http://www.phassociation.org/Learn/Consensus-Statements. Accessed February 17, 2007.

6. McLaughlin VV, Archer SL, Badesch DB, et al. ACCF/AHA 2009 expert consensus document on pulmonary hypertension. A report of the American College of Cardiology Foundation task force on expert consensus documents and the American Heart Association developed in collaboration with the American College of Chest Physicians; American Thoracic Society, Inc; and the Pulmonary Hypertension Association. Circulation. 2009;119(16):2250-2294.

7. Keogh AM, McNeil KD, Wlodarczyk J, Gabbay E, Williams TJ. Quality of life in pulmonary arterial hypertension: improvement and maintenance with bosentan. J Heart Lung Transplant. 2007;26(2):181-187.

8. Piña IL, Apstein CS, Balady GJ, et al. Exercise and heart failure: a statement from the American Heart Association Committee on exercise, rehabilitation, and prevention. Circulation. 2003;107(8):1210-1225.

9. Nici L, Donner C, Wouters E, et al. American Thoracic Society/European Respiratory Society statement on pulmonary rehabilitation. Am J Respir Crit Care Med. 2006;173(12):1390-1413.

10. Uchi M, Saji T, Harada T. Feasibility of cardiopulmonary rehabilitation in patients with idiopathic pulmonary arterial hypertension treated with intravenous prostacyclin infusion therapy. J Cardiol. 2005;46(5): 183-193.

11. Mereles D, Ehlken N, Kreuscher S, et al. Exercise and respiratory training improve exercise capacity and quality of life in patients with severe chronic pulmonary hypertension. Circulation. 2006;114(14): $1482-1489$.

12. De Man FS, Handoko ML, Groepenhoff H, et al. Effects of exercise training in patients with idiopathic pulmonary arterial hypertension. Eur Respir J. 2009;34(3):669-675.

13. Shoemaker MJ, Wilt JL, Dasgupta R, Oudiz RJ. Exercise training in patients with pulmonary arterial hypertension: a case report. Cardiopulm Phys Ther J. 2009;20(4):12-18.

14. Mainguy V, Maltais F, Saey D, et al. Effects of a rehabilitation program on skeletal muscle function in idiopathic pulmonary arterial hypertension. J Cardiopulm Rehab Prev. 2010;30(5):319-323.

15. Fox BD, Kassirer M, Weiss I, et al. Ambulatory rehabilitation improves exercise capacity in patients with pulmonary hypertension. J Cardiac Fail. 2011;17(3):196-200.

16. Sun XG, Hansen JE, Oudiz RJ, Wasserman K. Exercise pathophysiology in patients with primary pulmonary hypertension. Circulation. 2001; 104(4):429-435.

17. Barst R. Evaluation and treatment for angina in pulmonary arterial hypertension. Am J Med. 2004;116(6):427-428.

18. Gabbay E, Reed A, Williams TJ. Assessment and treatment of pulmonary arterial hypertension: an Australian perspective in 2006. Intern Med $J$. 2007;37(1):38-48.

19. Australian Bureau of Statistics. Population clock. Available at: http:// www.abs.gov.au/ausstats/abs@nsf. Accessed November 11, 2010.

20. Medicare Australia. Primary pulmonary and pulmonary arterial hypertension. Available at: http://www.medicareaustralia.gov.au/ provider/pbs/drugs2/hypertension.jsp. Accessed August 22, 2010. 


\section{Appendix I}

Questionnaire used in the study together with the responses to each questions.

Note: Data given in the responses are number of responses with percentages given in parentheses.

\section{Activity and exercise guidelines for patients with pulmonary arterial hypertension (PAH) Background}

There is very little in the literature to guide exercise and physical activity recommendations for patients with PAH. The
Royal Perth Hospital Advanced Lung Disease/Pulmonary Hypertension Research Group led by Associate Professor Eli Gabbay, in conjunction with the Curtin University School of Physiotherapy, is seeking to determine expert opinion on exercise and physical activity guidelines for patients with $\mathrm{PAH}$. We therefore request that you complete and return the following questionnaire.

Participation is purely voluntary but we strongly encourage your contribution. There is no individual identifying information on this questionnaire and therefore anonymity will be protected. Information gained from this questionnaire may be used in future presentations and publications.

Thank you for taking the time to complete this questionnaire.

For each of the following questions please circle your chosen answer.

$\begin{array}{ll}\text { Total number of respondents } & \begin{array}{l}\text { Results } \\ (\mathbf{n}=\mathbf{5 3})\end{array} \\ \text { Type of institution: } & \mathbf{n}(\mathbf{\%}) \\ \text { a) Tertiary/major hospital } & 41(77) \\ \text { b) Secondary/regional hospital } & 8(15) \\ \text { c) Private practice } & 3(6) \\ \text { d) General practice } & 0 \\ \text { e) Other - please specify___ } & 1(2)\end{array}$

\section{Position:}
a) Respiratory (thoracic) physician
$19(36)$
b) Cardiologist
$8(15)$
c) Rheumatologist
$6(11)$
d) Nurse specialist
19 (36)
e) Exercise physiologist
$1(2)$
f) Other - please specify

Number of new PAH patients seen per year:
a) $0-10$
$18(34)$
b) $11-50$
c) 51-100
d) 101-150
4 (8)
e) 151-200
0
f) $201-300$
g) $>300$
0

Two case studies are presented. Please circle the answer(s) that best represents your usual response.

\section{Case 1}

44-year-old female

\section{WHO functional Class IV}

Six-minute walk distance $85 \mathrm{~m}$ on room air.

ABGs on room air $\mathrm{PaO}_{2} 51 \mathrm{mmHg}(6.8 \mathrm{kPa}), \mathrm{PaCO}_{2} 42 \mathrm{mmHg}(5.6 \mathrm{kPa})$

PAP 92/55, mean PAP $67 \mathrm{mmHg}$ on resting RHC study

PVRI $2291 \mathrm{dyne} / \mathrm{s} / \mathrm{m}^{2} / \mathrm{cm}^{5}$ 
Severely dilated right ventricle with severe global impairment of RV systolic function

No evidence of thromboembolic disease

All usual tertiary hospital-based assessment related to diagnosis and medical management has been performed

In relation to exercise and activity prescription:

Results

1. What further investigations would you perform? n (\%)
a) None
$28(53)$
b) Exercise right heart catheter
$8(15)$
c) Exercise echo
d) Other - please explain

Results: lung function tests $(n=2)$, cardiopulmonary exercise test (CPET) $(n=1)$, CT angiogram $(n=1)$, overnight oximetry $(\mathrm{n}=1)$

In the absence of these results:

2. What instructions for daily activities would you give?
a) None
0
b) Recommend only mild exertion
$12(23)$
c) Recommend moderate exertion
$2(4)$
d) Instruct the patient to continue activity as tolerated
$32(60)$
e) Other - please explain

Results: Refer to physio/pulmonary rehab $(n=6)$, oxygen therapy $(n=4)$, symptom limited exercise $(n=2)$, overnight oximetry $(\mathrm{n}=1)$

For this question, more than one answer may be selected

3. How would you guide the patient with respect to their daily activities? Would you:
a) Give verbal guidelines
$36(68)$
b) Give written guidelines
$19(36)$
c) Refer the patient for instruction
$12(23)$
d) Refer the patient for exercise rehabilitation
35 (66)
e) Other - please explain

For this patient, which of the following symptoms would you consider to be acceptable during daily activities?

4. Breathlessness
a) Minimal
$6(11)$
b) No more than moderate
$27(51)$
c) As much as the patient can tolerate
18 (34)
d) Other - please explain

5. Light-headedness
a) None
b) Mild
c) Moderate
3 (6)
d) To the point of syncope
0
e) Other - please explain

6. Fatigue
a) None
$1(2)$
b) Minimal
15 (28) 
c) Moderate fatigue $26(50)$

d) As much as the patient can tolerate 9 (17)

e) Other - please explain

7. Chest pain
a) None
$36(68)$
b) Mild
$16(30)$
c) Moderate
0
d) As much as the patient can tolerate
$1(2)$
e) Other - please explain

Following 6 months on a maximal dose of Epoprostenol this same patient has the following results:

\section{WHO functional class II}

6MWD $405 \mathrm{~m}$ on room air

Echo: mild RV dysfunction and RV dilatation

Mean PAP $45 \mathrm{mmHg}$

PVRI 815 dynes $/ \mathrm{s} / \mathrm{m}^{2} / \mathrm{cm}^{5}$

8. What further investigations would you perform? n (\%)
a) None
$36(68)$
b) Exercise right heart catheter
$5(9)$
c) Exercise echo
$3(6)$
d) Other - please explain

Results: Six-minute walk test $(6 \mathrm{MWT})(\mathrm{n}=1)$, CPET $(\mathrm{n}=2)$

In the absence of any other results:

9. What instructions for daily activities would you give?
a) None
0
b) Recommend only mild exertion
c) Recommend moderate exertion
d) Instruct the patient to continue activity as tolerated
e) Other - please explain

Results: Assess exercise capacity/6MWT $(n=3)$, review by physio/continue pulmonary rehab $(n=2)$, oxygen therapy $(\mathrm{n}=2)$, symptom limited exercise $(\mathrm{n}=3)$

For this question, more than one answer may be selected

10. How would you guide the patient with respect to their daily activities? Would you:
a) Give verbal guidelines
38 (72)
b) Give written guidelines
$20(38)$
c) Refer the patient for instruction
9 (17)
d) Refer the patient for exercise rehabilitation
$33(62)$
e) Other - please explain

For this patient, which of the following symptoms would you consider to be acceptable during daily activities?

11. Breathlessness
a) Minimal
b) Moderate
c) As much as the patient can tolerate
$16(30)$
d) Other - please explain 


\section{Light-headedness}
a) None
$30(57)$
b) Mild
20 (37)
c) Moderate
2 (4)
d) To the point of syncope
0
e) Other - please explain

13. Fatigue
a) None
b) Minimal
18 (33)
c) Moderate
20 (37)
d) As much as the patient can tolerate
12 (22)
e) Other - please explain

14. Chest pain
a) None
$41(78)$
b) Mild
8 (16)
c) Moderate
$1(2)$
d) As much as the patient can tolerate
2 (4)
e) Other - please explain

Case 2

36-year-old female

\section{WHO functional Class III}

Six-minute walk distance $305 \mathrm{~m}$ on room air

ABGs on room air $\mathrm{PaO}_{2} 88 \mathrm{mmHg}(11.7 \mathrm{kPa}), \mathrm{PaCO}_{2} 38 \mathrm{mmHg}(5.1 \mathrm{kPa})$

PAP $62 / 28$, mean PAP $38 \mathrm{mmHg}$ on resting RHC study

PVRI $671 \mathrm{dyne} / \mathrm{s} / \mathrm{m}^{2} / \mathrm{cm}^{5}$

Moderately dilated right ventricle with moderate global impairment of RV systolic function

No evidence of thromboembolic disease

All usual tertiary hospital based assessment related to diagnosis and medical management has been performed. In relation to exercise and activity prescription:

Results

15. What further investigations would you perform? n (\%)
a) None
$27(51)$
b) Exercise right heart catheter
8 (15)
c) Exercise echo
8 (15)
d) Other - please explain

Results: Lung function tests $(n=1)$, CT pulmonary angiogram $(n=1), 6$ MWT $(n=1)$, overnight oximetry $(n=1)$

In the absence of these results:

16. What instructions for daily activities would you give?
a) None
0
b) Recommend only mild exertion
7 (13)
c) Recommend moderate exertion
5 (9)
d) Instruct the patient to continue activity as tolerated
$30(57)$
e) Other - please explain
7 (13)

Results: Assess exercise capacity $(n=1) / 6 M W T(n=2) /$ exercise right heart catheter $(n=1)$, cardiac or pulmonary rehab $(n=2)$, oxygen therapy $(n=1)$, symptom limited exercise $(n=3) /$ no strenuous exercise/Borg $<6$ 
For this question, more than one answer may be selected

17. How would you guide the patient with respect to their daily activities? Would you:
a) Give verbal guidelines
b) Give written guidelines
c) Refer the patient for instruction
14 (26)
d) Refer the patient for exercise rehabilitation
$32(60)$
e) Other - please explain

For this patient, which of the following symptoms would you consider to be acceptable during daily activities?

18. Breathlessness
a) Minimal
$14(26)$
b) Moderate
$20(38)$
c) As much as the patient can tolerate
$15(28)$
d) Other - please explain

19. Light-headedness
a) None
$27(51)$
b) Mild
$20(38)$
c) Moderate
2 (4)
d) To the point of syncope
0
e) Other - please explain

20. Fatigue
a) None
$4(8)$
b) Minimal
c) Moderate
18 (34)
d) As much as the patient can tolerate
$13(25)$
e) Other - please explain

21. Chest pain
a) None
$39(74)$
b) Mild
7 (13)
c) Moderate
2 (4)
d) As much as the patient can tolerate
$1(2)$
e) Other - please explain

Please circle either the yes or no response to each of the questions below:

22. For a patient with established PAH in WHO functional class II would you advise:
a) Lifting $20 \mathrm{~kg}$ in weight
b) Exercising in a non-hospital gym
Yes $(19,36)$ No $(30,57)$
c) Regularly using stairs and slopes
Yes $(37,70)$ No $(12,23)$
d) A sedentary lifestyle
Yes $(42,79) \quad$ No $(7,13)$
Yes $(1,2) \quad$ No $(48,91)$

Results (n, \%) (n, \%)

23. For a patient with established PAH in WHO functional class III would you advise:
a) Lifting $20 \mathrm{~kg}$ in weight
Yes $(5,9) \quad$ No $(44,83)$
b) Exercising in a non-hospital gym
Yes $(11,21) \quad$ No $(38,72)$
c) Regularly using stairs and slopes
Yes $(27,51) \quad$ No $(22,42)$
d) A sedentary lifestyle
Yes $(4,8) \quad$ No $(45,85)$

24. For a patient with established PAH in WHO functional class IV would you advise:
a) Lifting $20 \mathrm{~kg}$ in weight
Yes $(0) \quad$ No $(49,92)$
b) Exercising in a non-hospital gym
Yes $(3,6) \quad$ No $(46,87)$ 
c) Regularly using stairs and slopes

d) A sedentary lifestyle
Yes $(6,11) \quad$ No $(43,81)$

Yes $(9,17)$ No $(40,75)$

\section{Further comments about exercise/activity instructions, or the questionnaire:}

\section{Results:}

1) Important all patients given an exercise prescription based on professional, experienced assessment (eg, physio); avoid heavy lifting and anaerobic activity; avoid breath holding (eg, during swimming)

2) Exercise to tolerance after supervised exercise in hospital gym for all class II/III patients

3) As good as a drug. Should be used in all cases

4) Most patients in WHO II and III could do a rehab program but it would be PH related and most would benefit from one-on-one supervised training with a specialist

5) For majority of patients exercise is advisable in consultation with treating physician and physiotherapist/pulmonary rehab co-ordinator in a monitored environment. Activity is always recommended however should be adjusted to patients' condition. Isometric exercises, gentle walking, and use of oxygen should be discussed individually with patients and carers.

Thank you again for your participation.

A/Prof Sue Jenkins is a lecturer and Robin Fowler is a PhD student at Curtin University.

If you wish to be informed of the collective results of this survey, please contact Robin Fowler via email at the following address:

\section{Robin.Fowler@health.wa.gov.au}

Postal address:

c/ Advanced Lung Disease Unit

Royal Perth Hospital

Ainslie House, Murray Street

Box X2213 GPO

Perth 6847

Western Australia

\section{Publish your work in this journal}

The Journal of Multidisciplinary Healthcare is an international, peerreviewed open-access journal that aims to represent and publish research in healthcare areas delivered by practitioners of different disciplines. This includes studies and reviews conducted by multidisciplinary teams as well as research which evaluates the results or conduct of such teams or healthcare processes in general. The journal covers a wide range of areas and welcomes submission from practitioners at all levels, from all over the world. The manuscript management system is completely online and includes a very quick and fair peer-review system. Visit http://www.dovepress.com/testimonials.php to read real quotes from published authors. 